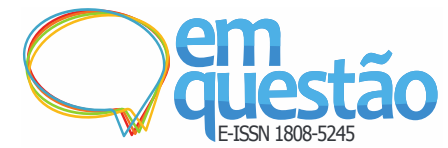

\section{Rememorando o perigo: os discursos da mídia nas sucessivas retomadas dos grandes acidentes de origem científico-tecnológica}

\author{
Maria da Conceição da Rocha Ferreira \\ Doutora; Universidade Federal do Estado do Rio de Janeiro, Rio de Janeiro, RJ, Brasil; \\ mferreira@cnen.gov.br \\ Evelyn Goyannes Dill Orrico \\ Doutora; Instituto Brasileiro em Informação e Tecnologia, Rio de Janeiro, RJ, Brasil; \\ evelynorrico@unirio.br
}

\begin{abstract}
Resumo: Embora focando o discurso jornalístico, este artigo discute a relação entre a informação apresentada em veículo de comunicação e sua repercussão no imaginário social. Essa aproximação entre as questões informacionais e as comunicacionais permite refletir teoricamente a respeito de seus impactos sobre a construção simbólica da população que recebe a informação. Além disso, ilustra o aparato teórico que estabelece relação direta entre informação e memória. É o que será abordado neste artigo. A referência a alguns dos piores desastres no cenário mundial leva em consideração aqueles que tiveram maior efeito sobre as pessoas e o meio ambiente. Observar os discursos jornalísticos empregados nos aniversários de grandes tragédias pode ajudar a descobrir o que pode ser apreendido em relação à essas rememorações periódicas que a mídia realiza, no intuito de compreender seu impacto no imaginário social. A rememoração cíclica dos grandes acidentes mundiais é o viés escolhido para analisar a memória de construção do discurso provocador do medo atômico. Trabalha-se com as múltiplas representações que a ideia de tempo pode ter dentro do jornalismo e observa-se que, ao celebrizar este ou aquele acontecimento, repetindo-o a cada período de tempo, a mídia se aproveita dele para autopromoção. O tempo e a memória representam estratégias discursivas para o jornalista, pois os vários usos do passado podem construir novas redes de sentido aos acontecimentos atuais, fazendo com que o valor-notícia desses fatos aumente. Como ilustração dessa premissa, analisam-se alguns artigos de celebrações de acidentes de origem nuclear: Chernobyl, em 1986, e Fukushima, em 2011, através dos quais, devido à uma distância temporal de 25 anos, é possível observar e ponderar sobre os discursos pré-construídos e os discursos transversos a esses acontecimentos, em um processo histórico de interpretação e de disputa na produção de sentidos.
\end{abstract}

Palavras-chave: Risco científico. Discurso. Mídia. Memória. Celebração. 


\section{Introdução}

O sentimento de medo que parece atingir a uma grande parcela da humanidade, em se tratando de tecnologia nuclear, nos sugere um fundamento na imagem do cogumelo formado pela explosão das bombas lançadas em Hiroshima e Nagazaki. Além de marco histórico, este é um símbolo de imensa tragédia humana e ambiental que está irremediavelmente associado ao nascimento da descoberta científica do poder do átomo. A informação que transmitida por essa imagem quando a bomba foi lançada, pouco se transformou ao longo do tempo. A relação que se estabelece entre o sentimento de medo e a descoberta científica é a que se constrói entre memória e informação. Considerando a informação, segundo Belkin (1976), como algo que transforma estruturas e a memória como algo construído pelas vivências e pelo discurso, defendemos que a mídia, aqui especialmente o jornalismo, é um forte meio difusor de informação, ao mesmo tempo em que constrói memórias.

Essa última afirmação baseia-se na percepção de que, ao difundir-se, à época do seu lançamento, a novidade da bomba atômica, a estrutura cognitiva de grande parte da população mundial foi alterada por essa informação que passou a constituir um universo simbólico sobre essa descoberta da ciência do século XX. A partir dessa transformação, a relação que a mídia permanece estabelecendo entre aquela informação e as novas situações consolida uma determinada construção simbólica da realidade que se manifesta na memória sobre esses fatos. A informação deixa de transformar estruturas para reforçar crenças já construídas, sobretudo quando se aproveita de eventos de semelhantes naturezas para consolidar a crença existente.

A data da detonação das bombas é comemorada mundialmente em um ritual que se repete a cada ano como aniversário de uma tragédia humana, rememorada em exemplo do que nunca mais deveria se repetir. Além desse fato, que marca uma inovação bélica e para sempre associará a energia atômica à fúria da guerra e à destruição desenfreada, temos também as comemorações de acidentes que marcaram época por conta de suas consequências extremamente danosas: a cidade de Chernobyl, na Ucrânia, ficou celebrizada mundialmente pela explosão de um reator, em 26 de abril de 1986, da usina que ali se 
localizava, e que cuja radiação contaminou uma área de 200 mil km² da Europa; e em março de 2011, em Fukushima, no Japão, um tsunami de nível sem precedentes atingiu a usina do local e provocou o derretimento de três dos seis reatores da usina. Nesses exemplos, consegue-se ilustrar quão próximo a informação encontra-se da memória.

A estranheza que pode causar, ao senso comum, o termo comemoração, para referirmo-nos aos aniversários de acontecimentos tão trágicos como os acidentes objeto deste trabalho, precisa de uma consideração inicial. Usamos os termos rememoração e comemoração como noções teóricas que funcionam juntas no eixo da formulação do discurso. Enquanto a rememoração aproxima-se da recordação do passado, de uma anterioridade, e usa de argumentos de legitimação, buscando garantir a fidelidade do narrado; a comemoração referese à atualidade, à releitura de um fato social, que pode trazer tanto aceitação como crítica (SILVA, 2002).

Diante disso, podemos chamar a memória constitutiva da rememoração como aquela que dá significado aos grupos sociais. Mais do que uma informação que transforma estruturas, ela constrói a memória que vai consolidar o reconhecimento do grupo enquanto tal. Mas, ao mesmo tempo, essa memória faz parte da comemoração, enquanto lhe dá o motivo de ritualização, quando a traz para o presente. Explicando melhor, a rememoração funciona na verticalidade, como um discurso do que passou e é trazido para o presente; já a comemoração entende-se na horizontal, ou um discurso sobre o fato marcado e ritualizado.

Os grandes acidentes de causa científico-tecnológica são nosso objeto de discussão porque eles aproximam dois campos: o primeiro é o da divulgação científica e o segundo, o da construção da memória. Fora dos desastres que têm origem na exploração nuclear, merece destaque nos registros da memória desse tipo de acontecimento o vazamento de gases tóxicos em Bhopal, na Índia. Na madrugada de 3 de dezembro de 1984, quarenta e cinco toneladas de gases vazaram de um tanque da fábrica de agrotóxicos da Union Carbide e cerca de 2.500 pessoas morreram pelo contato com as substâncias letais, além de outras 150 mil sofrerem com queimaduras nos olhos e pulmões. Completando 30 anos 
em 2014, a imprensa internacional relatou manifestações da população da Índia pedindo compensações maiores aos sobreviventes e punições mais severas aos responsáveis.

Em termos de controle de riscos, tanto à saúde humana quanto aos danos ambientais, aqui no Brasil não estamos muito diferentes da Índia de 30 anos atrás. $\mathrm{O}$ investimento na prevenção se mostra insuficiente e o mesmo ocorre quanto à punição de culpados. Basta lembrar que recentemente nos deparamos com o desastre do rompimento de uma barragem em Mariana, MG, que pode ser considerado o maior acidente mundial com barragens em um período de até 100 anos. Ao todo, 39 cidades foram afetadas e a fauna e a flora do Rio Doce sofreram danos irreparáveis. Quanto às punições dos culpados, até o presente momento, nenhuma condenação foi feita.

Enfim, outros acidentes no campo da mineração também podem ser citados como exemplos de graves falhas da política nacional de regulamentação do setor, e o que nos concerne é que urgem as ações governamentais para que se identifiquem as causas e se possam evitar novas falhas de consequências tão destruidoras. Nesse sentido, entendemos que as práticas informacionais são importantíssimas para construir o imaginário sobre as formas de proteção aos mais diversos agentes de perigo.

Todas essas ocorrências remetem-nos a pensar quais são de fato "os ingredientes" que fazem celebrizar, em maior ou menor grau, os desastres ocasionados por falhas humanas e que carecem de um cuidado maior para que não mais ocorram. Os acidentes no campo da mineração e na indústria química são de fato muito graves. E ocorrem com tanta frequência ou até mais do que se observa na energia atômica. Mas acreditamos que pode haver uma distinção de abordagem info-midiática no tratamento dessas modalidades. A rememoração da bomba nuclear, da ameaça de destruição por contaminação radioativa, é uma hipótese que nos parece válida como sustento a uma comemoração de acidentes de origem nuclear - algo a mais que os caracteriza como um valor de lembrança.

Parece-nos, além disso, que os acidentes permanecem nas narrativas posteriores para nos lembrar da fragilidade que experimentamos para nós mesmos diante da magnitude de nossa ciência. A cada período de tempo 
abarcado, retomam-se os danos causados e avaliam-se as atitudes tomadas na prevenção das falhas apontadas, mas não somente isso. Observar os discursos jornalísticos, que veiculam informações dessa natureza nos aniversários de grandes tragédias, pode nos ajudar a ver o que mais pode ser apreendido em relação a esses fatos.

Que efeitos podem provocar o testemunho do trauma de um acidente do alcance daqueles, aqui anteriormente enumerados? Erikson (1994), ao tratar de um acidente semelhante à tragédia de Mariana, o rompimento da barragem de Bufalo Creek, nos EUA, argumenta que as catástrofes tecnológicas nunca são bem compreendidas por quem lhes está sujeito. Como um produto do desenvolvimento do mundo, essas "fatalidades" provocam indignação mais do que resignação. O sentimento é de que, se houve erros, tem que haver punição de culpados. Mas, o mais importante é que, em tais catástrofes, são provocados sentimentos de dano e vulnerabilidade dos quais é difícil recuperar-se. Bufalo Creek, tal como Mariana, foi um acidente de grande repercussão desde a sua ocorrência em 1972, um exemplo emblemático de como a negligência industrial e a ganância empresarial podem equacionar uma tragédia de impressionante magnitude. Erikson nos reporta que, quatro dias antes do rompimento de Bufalo Creek, a barragem havia sido declarada "satisfatória" pela inspeção federal, sugerindo uma falha na fiscalização governamental. Já no caso de Mariana, o Ministério Público apontou negligência e abriu inquérito para apuração dos responsáveis, mas ainda não há condenados. Negligência, descaso e ambição, esta é a tríade estabelecida pela imprensa para reportar a atuação da mineradora Samarco, que colocou o aumento da produção acima da segurança e acabou causando o maior desastre dos últimos anos.

O que observamos nas retomadas das narrativas de acidentes que rememoram diferentes períodos de tempo, por diferentes núcleos sociais, são, primeiramente, os sintomas de trauma. Não o trauma simplesmente individual, mas aquele que afeta as comunidades que experimentam uma tragédia como as aqui citadas. Interessa-nos observar que uma experiência traumática pode se transformar em elaborações, por mínimas que sejam, em termos criativos de construção de uma memória e, assim, constatamos na experiência traumática, 
com seus efeitos negativos e positivos, a construção de representações como soluções para o sujeito afastar-se do terror causado pelo choque decorrente desse trauma (FARIAS; PINTO, 2016).

A tese de doutorado, da qual este trabalho é fruto, segue na investigação de como se constrói a memória de cultura do risco ou perigo da tecnologia nuclear. Neste artigo, aproveitamos para analisar um aspecto da memória de construção do discurso provocador desse medo, pelo viés da rememoração que ocorre em ciclos de tempo, como marcação de aniversários. Essa necessidade de rememoração da tragédia passada pode nos trazer um material diversificado quando se trata do papel da mídia na elaboração discursiva posterior a acidentes de origem científico-tecnológica.

Da mesma maneira, refletimos sobre o que representam, para o campo da ciência da informação, as veiculações desses acidentes pela mídia. Sendo uma tarefa inerente ao seu fazer investigativo tentar mapear os limites de campos do conhecimento, traçando uma mediação entre interesses de informação e os bancos de dados dos registros dessa informação, observamos seus limites enquanto campo atuante junto à memória social, que é interdisciplinar. Dodebei e Orrico (2012) ressaltam a afinidade conceitual desses dois campos que trabalham com uma importante dimensão discursiva, a partir da qual se estabelece um universo simbólico, pelo qual uma rede de sentidos se constitui.

\section{Jornalismo e a multiplicidade do tempo social}

Para refletir sobre o tempo, mais especificamente o passado, devemos, inicialmente, distinguir o tempo físico, aquele que se define em cronologia. A noção newtoniana clássica de tempo propõe que ele é linear, contínuo, uniforme e infinitamente divisível e que avança numa reta geométrica. Mas Elias (1998) descreve uma segunda categoria, que denomina de tempo social - uma construção simbólica que se articula a uma dimensão material e se institucionaliza em práticas e regulações. Sobre essa ideia de tempo, aliás, relacionamos a ideia de memória. Nós a vemos como a construção de um passado pela consciência, no presente, de um grupo social. 
Paul Ricoeur (1994) diz que o tempo torna-se tempo humano na medida em que está articulado de modo narrativo. Poderíamos dizer, dessa forma, que o tempo e a narrativa podem ser percebidos a partir de uma experiência histórica. Contudo, lembrar o passado e escrever sobre ele implica em uma seleção do narrador sobre o que vai ser lembrado. Nessa mesma linha, Mariani (1993) acrescenta a memória como um processo histórico, resultante de uma disputa de interpretações para os acontecimentos presentes ou já ocorridos. Como resultado, vai predominar apenas uma de tais interpretações, havendo o esquecimento das demais. A autora coloca esse processo como uma naturalização de um sentido que se torna comum à sociedade, como um fio de uma lógica narrativa (MARIANI, 1988).

Algo semelhante ocorre com os acidentes nucleares que observamos. Desenvolveremos um raciocínio em torno do imaginário que se segue nas narrativas a respeito da experiência traumática específica dos acidentes de origem tecnológica, quando nos ocuparmos da análise dos discursos que envolvem essas narrativas em seus diferentes períodos de tempo, que convencionamos como tempo social. Por agora, vamos aproveitar essas noções iniciais de memória e narrativa para verificar a atuação jornalística no acompanhamento de acontecimentos memoráveis, que são periodicamente retomados pelas mais diversas motivações.

Franciscato (2009) investiga a atuação do jornalismo na construção do tempo social. Para ele, existem múltiplos tempos - e não apenas o cronológico, que são vividos, ou trazidos ao plano da reportagem, como se fossem um único tempo presente. O autor observa que o jornalismo atua de forma privilegiada no reforço de uma temporalidade social, já que produz formas específicas de sociabilidade. Ao atuar como um agente modelador das notícias, o tempo e a memória representam para o jornalista estratégias discursivas que trazem sentido aos acontecimentos atuais, aumentando seu valor-notícia. Na verdade, manter a coerência temporal é um fundamento dos recursos narrativos para manter a continuidade da história, com o consequente engajamento dos leitores, proporcionando visibilidade ou notoriedade à notícia. Da celebração de aniversários à retrospectivas de final de ano, o jornalismo age conectando o 
passado e o presente, demonstrando aos seus leitores o que eles deveriam lembrar.

A questão que fica é quais fatos do passado, assim como alguns de seus aspectos, são trazidos pelo jornalismo nessa estratégia discursiva. Nesse sentido, o que é publicado não é completamente novo, portanto não seria uma informação que alteraria a estrutura cognitiva do interlocutor, mas, ao contrário, um reforço de crença. Mesmo assim, se atentarmos para o fato de que esse reforço de crença impede que o assunto seja esquecido, voltamos a ver que existe informação, já que mantém o tema atual, ativando uma outra dimensão complementar: a da memória.

As celebrações são significadas, entendidas e vividas num ritmo próprio, assinalado, por exemplo, por espaços temporais de cinco, dez ou vinte anos. $\mathrm{O}$ acidente de Chernobyl se encaixa perfeitamente nesse modelo de celebração em tempo cíclico, onde há uma tendência de continuidade e circulação em torno de uma mesma referência temporal que vai além do passado, presente e futuro, sendo semelhante a uma ideia de eternidade (FRANCISCATO, 2009). Ao completar 30 anos em 2016, comprovamos sua regularidade cíclica nos títulos das manchetes que a seguir transcrevemos:

a) Dez anos de Chernobyl, Folha de São Paulo, 26/09/1996 (SILVA JÚNIOR, 1996);

b) Vigília lembra 20 anos do desastre de Chernobyl, Reuters, de 25/04/2006 (KARAZY, 2006);

c) Com minuto de silêncio, milhares lembram tragédia em Chernobyl, Folha de São Paulo, de 26/04/2006 (FOLHA..., 2006);

d) Chernobyl: pior acidente nuclear da história completa 30 anos, de Veja, em 26/04/2016 (VEJA, 2016).

Da classificação de Franciscato (2009), que compõe-se de 8 itens de aplicação do tempo social segundo o olhar midiático, neste trabalho nos ocupamos do tempo cíclico. Porque as lembranças que guardamos de acontecimentos marcantes podem ser presentificadas segundo diferentes forças que lhes disputam a representação. A contagem do tempo, neste caso, age na produção de significações que se processam em uma temporalidade repetitiva, 
como é o caso dos aniversários, seja de traumas sociais, como os acidentes e outras tragédias ambientais e humanitárias; seja de eventos sociais de repercussão positiva. $\mathrm{O}$ fato é que a celebração de aniversários expressa uma das muitas representações da vida social e nos instiga à investigação, sobretudo quando o acontecimento é algo traumático como os acidentes de grandes proporções aqui citados. Silva (2007) classifica com muita propriedade as celebrações de aniversários desse tipo como invocação de ritos de passagem. $\mathrm{O}$ tempo cíclico assinala, nesses casos, transições de vida ou renascimentos. Marca o pertencimento a uma identidade social reverenciada pela memória de tal acontecimento que se atualiza nesse ritual de celebração. Vamos nos ocupar, mais adiante, do ritual de aniversários de morte, palavra que resume melhor o acidente como acontecimento celebrado. Antes, precisamos refletir sobre lembranças e esquecimentos que estão contidos nessas celebrações do tempo cíclico e os rituais que assinalam suas manifestações culturais.

A memória coletiva, na visão de Halbwachs (1990), é sempre construída em relação a quadros sociais e isso implica pensar no grupo do qual se faz parte. É bom lembrar que há um sistema simbólico que integra essa memória social e que caracteriza as associações culturais em seu esforço por rememoração e localização das lembranças. Esse simbólico aponta para as instituições e a comunicação midiática pelas quais os grupos sociais constroem seu passado comum, já que é através dos símbolos que o conhecimento do passado, aliás, qualquer forma de conhecimento, se propaga. Barbosa (1994) nos aponta que a mídia atua como um dos senhores da memória da sociedade, porque ela tem grande poder de determinar o tema que se mantém à tona, ou aquele que submergirá no esquecimento. Nesse sentido é que acreditamos que a mídia molda a memória, na medida em que exerce o papel de atualizar - ou não os assuntos para seus leitores.

O maior poder do discurso jornalístico está naquilo que se repete, que vai definindo como é o mundo, quais são os valores contemporâneos e sobre como agir neste mundo narrado. De alguma forma, os acontecimentos vão definir uma sociedade. Funcionando como um lugar de memória, onde a própria cultura dessa coletividade se instala, o discurso jornalístisco faz com que o passado 
perdure e, com ele, o filtro de sua ótica acerca desse passado. Na contemporaneidade, não existe memória coletiva que não seja em parte jornalística. Erll e Nünning (2008) ressaltam essa acepção, afirmando que o pensamento cultural de um determinado grupo social corresponde ao pensamento da mídia porque, ao selecionar o que deve ser divulgado, valorizando alguns elementos e outros não, é ela que vai determinar, para a sociedade, o que deve ser lembrado e o que precisa ser esquecido.

Esta é uma questão que repercute também para a Ciência da Informação, na forma como ela organiza suas referências autorais das pesquisas em Memória Social e o que ela representa para a humanidade. Dodebei e Orrico (2012) revisitam o modelo teórico do campo, agregando-lhe reflexões quanto à produção do conhecimento quanto ao patrimônio, à linguagem, à subjetividade e à informação. Assim, aproveitamos os resultados alcançados por esse trabalho de articulação entre conceitos e discursos, para utilizar da metáfora ontológica 'memória é cultura' na organização dos sentidos que as análises discursivas destas veiculações parecem perpetuar.

As matérias que selecionamos para a tese de doutorado, terminada recentemente, e que versa sobre a construção do discurso do medo do nuclear, tratam não apenas de aniversários de acidentes, mas das percepções dos riscos que os envolvem. Além dos acidentes de origem relacionada ao nuclear/radiológico, que são o foco principal, também focamos nas matérias sobre as falhas tecnológicas em geral. O critério seguido para a seleção do corpus de análise, nos parecendo o mais indicado, foi a dimensão do impacto de dano causado, tanto ao homem quanto ao ambiente. Quisemos observar o discurso empregado pelo jornalismo nesses determinados espaços de tempo, que operam em um ciclo de 10, 20 e 30 anos, para que fosse possível observar quais aspectos chaves dessas tragédias foram selecionados pelo jornalismo em cada época, o que foi destacado e o que pode ter sido omitido, intencionalmente ou não.

Entre os resultados do estudo empreendido por Dodebei e Orrico (2012), quanto à literatura de memória social indexada à ciência da informação, nos interessaram sobretudo as relações associativas para a formação dos sintagmas 
representativos dos discursos que enquadram o domínio da memória social. Sabemos que essas relações sintagmáticas se constroem pelo contexto discursivo, “[...] o que lhes garantirá representatividade no domínio da memória social.” (DODEBEI; ORRICO, 2012, p. 8).

Com o objetivo maior de acompanhar como se verificou e ainda se verifica a construção do discurso do medo nuclear ou atômico, nos será possível observar diferentes condições de produção desse discurso informacional, a partir de cenários políticos diversos e movimentações sociais diversas, sempre usando por referência o universo de grandes acidentes de causa tecnológica. Nosso intuito maior é compreender como esse discurso constrói a memória sobre esses acidentes, de modo que seja possível construir o conhecimento desses dados informacionais, para encará-los como forma de evitar que estes tipos de acidentes voltem a acontecer.

A memória social tem sido o foco de atenção de muitos pesquisadores de acidentes, naturais ou não, durante a última década. O que eles observaram é que os rituais e representações do passado, que são produzidos e consumidos por essa sociedade, formam o nervo central de suas memórias e narrativas - são as "verdades" que unificam tais sociedades, e isso fica evidente quando ocorre uma ruptura, como se pode chamar o trauma de um acidente. São as narrativas coletivas de uma comunidade que determinam como essa comunidade se identifica, suas circunstâncias e prospecções e são fator fundamental na forma como essas comunidades respondem a um desastre, o quão rapidamente vão responder, recuperar-se e voltar à normalidade (CHAMLEE-WRIGHT; STORR, 2011).

Em um trabalho sobre a destruição de Nova Orleans pelo furacão Katrina, Robinson (2009) posiciona-se sobre o papel da imprensa no relato das reações daquela comunidade. Embora não se trate de um acidente de causa tecnológica, como é nosso objetivo de pesquisa, as observações do autor demonstraram como a imprensa local e a nacional divergiram na cobertura do fato e como os primeiros aniversários puderam corrigir e sedimentar uma determinada história narrada. O jornalismo, neste caso, utilizando de sua propriedade de lidar com o tempo social, de selecionar lembranças e 
esquecimentos, desempenhou um papel garantidor à sociedade quanto à integridade de seus valores. A seguir, esmiuçaremos um pouco mais a utilização do tempo cíclico de que se vale não apenas o jornalismo, mas a sociedade de uma forma geral, quando se trata de rememorar o acontecimento que para ela se mostrou relevante.

\section{Celebrações de 5, 10, 20, 30 anos: uma memória retomada e construída}

A marcação de datas no calendário, conforme uma convenção social, sugere um significado maior e recebe a atenção de diferentes áreas de estudo. Os aniversários que assinalam não apenas a comemoração de uma conquista ou uma realização positiva, mas que, na verdade, trazem a memória de uma tragédia, despertam ainda, em nosso ver, um interesse singular. Quando se trata de grandes acidentes como os que nos referimos aqui, nossos objetos de estudo carecem, então, de maior cuidado na definição do que seriam seus aniversários. O conceito desenvolvido por Tardy e Dodebei (2015) de memoração, e que parte do francês mémoration, pode dar uma ideia mais completa do tema, pois aborda a memória social não como um simples fato social, mas como um processo que se analisa a partir da relação que a sociedade mantém com o tempo, o espaço, a linguagem e a criação. Assim são os marcos que memoram o acontecimento, na qualidade de instrumento da prática jornalística, ao construir uma dada memória da sociedade. Se a narrativa jornalística é marcada pela identidade com o instante já narrado e que se reatualiza por uma nova relação da sociedade com os fatores já citados, então, o passado é memorado e construído concomitantemente ao presente, moldado em uma realidade diferente daquela em que se deu o acontecimento original. Nesse jogo entre o que está no presente e o que foi deixado no passado existe a informação.

Chamam a atenção as marcas no calendário de determinados eventos, sendo esses fatos os destaques do dia a dia comum, como os feriados nacionais ou os dias santos do calendário católico. De alguma forma, tanto as celebrações festivas como as formas trágicas de celebração de aniversários servem para sedimentar um conjunto de significados sobre o passado e, nesse processo, naturalmente, também o presente. Pela celebração dos aniversários, podemos 
não apenas nos situar quanto ao fluxo incessante do tempo, mas, também, satisfazer a necessidade de manter uma história e sentir que fazemos parte dela.

Mas como será que se processam, especificamente, as celebrações de tragédias com grande impacto social, como os acidentes de grandes proporções, sendo ou não de origem tecnológica? Encarando-as por uma perspectiva antropológica, Turner (1982) esclarece que o evento traumático só passa a ser ritualizado coletivamente quando se processa a passagem da experiência de catástrofe para a experiência da redenção. Isso quer dizer que uma comunidade só escolhe datar um desastre e celebrar o seu pertencimento a esse evento, celebrando o seu aniversário, quando ela consegue associar as noções de superação e de sobrevivência às experiências vivenciadas na catástrofe. As ações em torno dos riscos de que se repitam tais acidentes, assim pensamos, podem também servir de compensação da dor que é relembrada. No mais, sendo a celebração do aniversário de um desastre, aparentemente, feita da mesma forma que qualquer aniversário, o primeiro ano tende a ser o mais significativo, porque os fatos vivenciados ainda estão muito vivos nas experiências cotidianas e a avaliação das medidas tomadas para remediação ou prevenção ainda é precoce. Depois, as lembranças submergem e reaparecem no período convencional de cinco anos e, na sequência, no ritmo de dez anos, vinte anos... No dizer de Chiaoning Su (2012), que faz um interessante trabalho sobre a cobertura midiática em torno do Grande Terremoto de Tawan em 1999 e outro no mesmo local, 10 anos depois, os aniversários de acidentes propiciam aos estudiosos a oportunidade de avaliar as relações entre os intervalos temporais arbitrariamente estabelecidos pela sociedade e a memória coletiva.

A memória discursiva, que integra o discurso de comemoração/ memoração dos acidentes, pode ser analisada nos eixos vertical e horizontal em um movimento em que a memória (rememoração) comporta as repetições e irrompe na comemoração (atualidade). Por vezes, o discurso se constrói em uma mesma filiação de sentidos, mas, em outras, os sentidos se relacionam a filiações e a lugares institucionais, que sustentam um diferente lugar de memória. Acreditamos que as comemorações fazem parte de um processo de exibição de poder, em que se destaca o interesse político de dominar o tempo. Entender a 
lógica da construção comemorativa como processo de reinstauração de uma memória dominante é compreender, também, a construção do acontecimento e a sua valoração pública. Os meios de comunicação dessa dimensão memorável se tornam, assim, os guardiões da única memória válida da sociedade (BARBOSA, 1994).

Vamos invocar aqui um acidente que, a exemplo de Chernobyl, pela proximidade de datas de ocorrência e pela semelhança das origens tecnológicas, tornou-se um marco na memória nacional: o césio 137 de Goiânia ${ }^{1}$, que fez trinta anos em 13 de setembro de 2017. Nesse período, os ciclos das celebrações de $5,10,25$ e 30 anos foram regularmente observados. Muitos trabalhos acadêmicos foram realizados em torno desse acidente por conta da sua localização nacional e sua notoriedade no exterior. Mas os dez anos foram especialmente marcados por conta de dois eventos que trouxeram significações conflitantes quanto às memórias da tragédia: o primeiro foi a inauguração do Depósito Definitivo de Rejeitos Radioativos e do Centro Regional de Ciências Nucleares do Centro-Oeste, que é filiado à Comissão Nacional de Energia Nuclear (CNEN), no então Parque Estadual de Abadia de Goiás; e o segundo, a realização da conferência internacional O Acidente Radiológico com o Césio 137: Goiânia Dez Anos (SILVA, 2007). Com o propósito de compartilhar os conhecimentos adquiridos - durante o evento trágico e nos anos seguintes - a conferência atraiu 400 participantes de 17 países. Nas palavras da CNEN, com essas realizações pelos 10 anos, se fazia um virar de página nesse triste capítulo da história brasileira (CONFERÊNCIA INTERNACIONAL..., 1998). Silva (2007) descreve que o sentido atribuído tanto pelas performances como pelas narrativas construídas corrobora uma tomada de controle da situação, deixando para trás o horror do acidente: os rejeitos radioativos, que por dez anos ficaram a céu aberto, estavam agora acomodados definitivamente e a CNEN assumia o compromisso de monitorar o local por mais cinquenta anos, ou seja, até 2047 (SILVA, 2007). Essa estratégia discursiva ilustra o que dissemos sobre interesse político de dominar o tempo e o acontecimento.

Defendemos a assertiva de que a memória social e o jornalismo mantêm estreita ligação e, quando se trata de celebrações de aniversários, podemos dizer 
que os jornalistas escrevem tanto a primeira quanto as versões subsequentes dos fatos a serem considerados para a história. De forma simultânea, exercem o papel de agentes de memória, narrando os fatos enquanto acontecem, e, com o passar dos anos, construindo a sua atualização. Porque a narração do fato, obedecendo a um ciclo que vai "reajustando" a história, primeiro faz o relato de eventos inesperados, possíveis e/ou previsíveis (aquilo para o que ainda não há memória), e seguindo uma ordem, ou seja, organizando filiações de sentidos possíveis para o acontecimento, vai construindo uma memória que se faz dos desdobramentos que esse acontecimento permitir perpetuar. Ao fazer a rememoração, com a atualização, sob a forma de comemoração, recolocando em circulação conteúdos que já haviam sido produzidos pelos próprios veículos midiáticos, o jornalismo age num processo de realimentação que se torna inesgotável: cada jornal já contém, armazenada em sua capacidade produtiva, os meios, os formatos e as informações para a produção de novos passados presentificados (OLICK, 2014).

Importa agora observar os acidentes, em sua ocorrência e na sua retomada, ou memoração. Os espaços de memória que se criam nesse tempo cíclico, naturalmente vão transformar, ou mesmo apagar, o já dito, uma vez que o movimento que se dá entre o espaço da rememoração e o da comemoração nem sempre é possível recuperar.

\section{Buscando lições - os discursos da mídia na retomada dos acidentes de origem nuclear}

Os artigos referentes a celebrações de acidentes de origem nuclear - Chernobyl, em 1986, e Fukushima, em 2011, além de semelhanças em termos de danos, apresentam também similaridades de abordagens. Em ambos, a mídia circunda com uma atmosfera de grave ameaça pela radioatividade, que tem consequências pouco definidas, além de morte. Ao mesmo tempo, há nuances de tratamento que uma distância temporal de 25 anos nos permite observar e ponderar, tanto quanto as diferentes condições de produção dos discursos dessas celebrações em tamanho período de tempo. Considerando que a ideologia é fundamental na $\mathrm{AD}$, é bom ressaltar que formações ideológicas diferentes 
materializam-se pela e na linguagem, já que a visão de mundo está a ela vinculada. E a linguagem tem seu sentido determinado ideologicamente. É pelas Formações Discursivas (FD) que as palavras ou expressões ganham sentido. Como define Orlandi (2007), a FD é aquilo que numa formação ideológica dada, ou seja, a partir de uma conjuntura sócio-histórica, determina o que pode e deve ser dito. Acrescente-se a essa argumentação em torno do discurso a memória do dizer, o que se chama em AD de interdiscurso. Porque o processo de significação, como nos diz Mariani (1998), integra três elementos: linguagem, pensamento e realidade, que se fazem intervir da memória do que já foi dito. Estabelecendo um diálogo com esse texto de Mariani, podemos dizer que os três elementos citados produzem um discurso de informação.

Um bom exemplo de ressignificação pelo interdiscurso - ou o já dito, encontra-se na sequência discursiva (SD) extraída da revista Isto É de 03/05/2006, na celebração dos 20 anos de Chernobyl: "Outro agravante é que o mesmo reator que gera energia pode ser empregado na fabricação de armas nucleares." (WIZIAK, 2006, doc. não paginado) Ao fazer a comparação dos usos da energia atômica para o bem (geração de energia) e para o mal (fabricação de armas), o jornalista estabelece a dicotomia de a favor x contra; positivo x negativo; que é bastante recorrente em reportagens que focalizam acidentes de origem nuclear. A partir do lado negativo, do mal, nos remetemos à memória discursiva, que, conforme Indusrsky (2011) diz respeito à existência histórica do enunciado no seio de práticas discursivas reguladas pelos aparelhos ideológicos. A referência remete à memória de Hiroshima, o fantasma que assombra a tecnologia, porquanto foi o lançamento da bomba que apresentou a energia nuclear ao mundo. É um interdiscurso que as celebrações de acidentes com essa origem vez por outra refletem.

Separamos, aqui, algumas sequências discursivas de referência (SDR), que são, na definição de Courtine (1982), fragmentos orais ou escritos maiores que a frase que possibilitam organizar um corpus analítico. Nesta análise, o que se pretende é uma reflexão sobre o funcionamento do discurso, permanecendo o objeto aberto para novas análises e abordagens. Todo discurso, ainda que considerado de forma isolada, em um contexto determinado, pode ser incluído 
num processo discursivo mais amplo. É a forma do recorte feito pelo analista que determina o modo de análise e o dispositivo teórico da interpretação construída. Afinal, consideramos que o espaço aberto na mídia para um fato já significa atribuir a ele uma importância e um sentido. Quando esse mesmo fato permanece, em suas múltiplas interpretações e facetas, sendo sucessivamente retomado, já demonstra um determinado processo discursivo.

Relacionamos as seis reportagens utilizadas como corpus de análise, na tabela 1, a seguir. Aqui, elas foram organizadas cronologicamente, conforme a apresentação das SDR's. Por uma questão de oportunidade, a conveniência das observações analíticas ocasionou uma ou outra referência cruzada entre as matérias analisadas, que procuramos identificar no momento em que ocorreram.

Quadro 1 - Relação de reportagens colhidas para análise discursiva

\begin{tabular}{|c|c|c|c|}
\hline Assunto & Revista & Data & Título da Matéria \\
\hline $\begin{array}{l}10 \text { anos de } \\
\text { Chernobyl }\end{array}$ & Folha de São Paulo & $26 / 09 / 1996$ & $\begin{array}{c}\text { Dez anos de Chernobyl } \\
\text { (SILVA JÚNIOR, 1996) }\end{array}$ \\
\hline $\begin{array}{l}20 \text { anos de } \\
\text { Chernobyl }\end{array}$ & Isto é & $03 / 05 / 2006$ & $\begin{array}{c}\text { Chernobyl ainda assombra } \\
\text { (WIZIACK, 2006) }\end{array}$ \\
\hline $\begin{array}{l}20 \text { anos de } \\
\text { Chernobyl }\end{array}$ & O Globo & $25 / 04 / 2006$ & $\begin{array}{c}\text { Vigília lembra 20 anos do desastre } \\
\text { de Chernobyl } \\
\text { (KARAZY, 2006) }\end{array}$ \\
\hline $\begin{array}{l}25 \text { anos de } \\
\text { Chernobyl }\end{array}$ & $\begin{array}{c}\text { BBC Brasil } \\
\text { Notícias }\end{array}$ & $26 / 04 / 2011$ & $\begin{array}{c}\text { Em meio a nova onda anti-nuclear, } \\
\text { Ucrânarca 25 anos de acidente } \\
\text { de Chernobyl (2011) }\end{array}$ \\
\hline $\begin{array}{l}30 \text { anos de } \\
\text { Chernobyl }\end{array}$ & Exame & $16 / 04 / 2016$ & $\begin{array}{c}\text { As cicatrizes nucleares 30 anos } \\
\text { após o inferno de Chernobyl } \\
\text { (BARBOSA, 2016) }\end{array}$ \\
\hline $\begin{array}{l}60 \text { anos da } \\
\text { bomba de } \\
\text { Hiroshima }\end{array}$ & G1 & $06 / 08 / 2011$ & $\begin{array}{c}\text { Kan defende o abandono da energia } \\
\text { nuclear no aniversário de } \\
\text { Hiroshima (FRANCE PRESSE, } \\
\text { 2011) }\end{array}$ \\
\hline
\end{tabular}

Fonte: Elaborado pelas autoras.

Reunimos nas SDR's 1, 2 e 3, a seguir, demonstrações de já ditos, ou interdiscursos que se fazem presentes em reportagens que tratam do tema nuclear. Neste caso, tendo como tema central o próprio acidente de Chernobyl. "SDR1: Mas o contínuo registro de acidentes demonstra que ainda não há aparato tecnológico para a execução de um sistema a prova de falhas." (SILVA JÚNIOR, 1996, doc. não paginado).

Pela conjunção adversativa "mas" que inicia o período, o autor nos aponta que seu enunciado irá quebrar expectativas, no caso, aquela relativa à 
existência de um sistema à prova de falhas. Observa-se, por este trecho, que o jornalista lança mão de um processo de antecipação em que ele parece tirar partido das relações de sentidos de discursos prévios (da ordem do interdiscurso), tentando antecipar o que seus leitores vão pensar. A antecipação do que o outro vai pensar, segundo Pêcheux (1990), parece constitutiva de qualquer discurso e é entendida como o momento em que o orador se faz de ouvinte, a partir de seu próprio lugar de orador, tentando apreender as formações imaginárias $(F I)^{2}$ desse ouvinte. "SDR2: Não há nada errado na utilização de usinas nucleares na geração de energia. Elas não emitem gases tóxicos na atmosfera nem despejam substâncias poluentes nos rios." (WIZIAK, 2006, doc. não paginado).

Por este recorte, observamos o interdiscurso de um movimento próecologia e de sustentabilidade, que acaba não se confirmando ao final da reportagem. Essa afirmação prepara terreno para a gradativa desconstrução da ideia de que a geração de energia limpa seja efetivamente realidade. Pode-se observar isso pelo trecho seguinte, que conclui pela temática do artigo em si: o aniversário de um acidente de abrangência global - "[...] sem contar, é claro, com as chances de acidentes como o de Chernobyl.” (WIZIAK, 2006, doc. não paginado).

Podemos observar no antagonismo que se sucede ao trecho da SDR2 uma relação de alteridade com uma segunda posição-sujeito. Para entender a ideia de sujeito em $\mathrm{AD}$, lembramos que nos referimos ao sujeito do discurso e não ao indivíduo. Esse sujeito discursivo é determinado por aspectos históricos, sociais e ideológicos, e se constitui pelo esquecimento, ou seja, ele tem a ilusão de que é o dono de seu dizer, mas que fala sempre a partir de um certo lugar, obedecendo ao que é determinado por uma certa FD. No entanto, apesar dessas determinações, o sujeito pode mover-se ora em direção a uma voz, ora em direção a outra, em um movimento de diferentes ordens de saber e diferentes sujeitos. Às diversas posições que o sujeito pode assumir num discurso, a $\mathrm{AD}$ denomina Posição-Sujeito, que se entende como a relação de identificação ocorrida entre o sujeito que enuncia e o sujeito do saber, que é o nome dado ao conjunto de conhecimento institucionalizado em uma FD - a 
Forma-Sujeito. Essa outra forma-sujeito da FD ocorre de forma a evidenciar uma FD de contradição, promovendo uma heterogeneidade discursiva. Promove, em uma visão superficial, um outro interdiscurso que circunda a tecnologia nuclear pelos impactos dos grandes acidentes repercutidos mundialmente: a falibilidade que se observa na indústria da produção nuclear de energia e que resulta em consequências irreparáveis. Remete-nos, naturalmente ao discurso da SDR1, de dez anos antes.

Avancemos mais dez anos, e observemos o trecho da SDR3, a seguir:

SDR3: Muitos outros estudos avaliam os efeitos de radiação sobre os seres humanos e a natureza dos $4.200 \mathrm{~km} 2$ da zona de exclusão da usina de Chernobyl. Em comum, revelam que o custo humano e ambiental real da tragédia de Chernobyl nunca será conhecido. (BARBOSA, 2016, doc. não paginado).

Por esse trecho, as informações são apuradas, ou, ao menos parecem ser. Dão um tom de verdade científica, em sua precisão de medida. O jornalista, aqui, é o sujeito que fala de um determinado lugar social, sendo afetado por diferentes relações de poder. O modo como ele discursiviza os diferentes saberes institucionais (tanto os vindos da ciência - "Muitos outros estudos avaliam", quanto os que circulam na ordem do senso comum - "o custo real da tragédia nunca será conhecido") sustenta e legitima socialmente o seu lugar (empírico) de agente social que controla a informação a ser - ou não veiculada, comprometido tanto com a verdade da ciência quanto com a verdade da mídia e com os saberes do leitor. A forma-notícia, como deliberamos chamar o resultado desse comprometimento jornalístico com ciência, conhecimento do leitor e a própria mídia, determina tanto o que é apresentado como fatos cotidianos quanto o que é apresentado como fatos da ciência. Da mesma forma que as implicações de um acidente acontecido há 10 ou 20 anos, uma eleição presidencial ou qualquer outra eventualidade de interesse popular, a informação no jornalismo científico assume uma forma autoritária, parafrásica com os discursos do poder da ciência institucionalizada, e tendente à ampla estabilização lógico-discursiva resultante da afirmação de que o custo humano e ambiental real da tragédia nunca será conhecido. 
Por este exemplo, lembramos que a $\mathrm{AD}$ apresenta um redirecionamento à ilusão da objetividade científica e/ou jornalística, sendo contrária à ideia que normalmente se assume de que a informação é algo livre de orientação ideológica. Ao afirmar que são muitos outros estudos, o jornalista quer passar uma segurança de conhecimento resultante de muitas pesquisas. Só que não revela o número exato. É uma técnica bastante usada de sugestão de embasamento epistemológico. A conclusão de que o custo nunca será conhecido se baseia nos tais muitos estudos dos quais não se sabe o número nem a modalidade científica, e muito menos há condição de auferir autoria.

Os trechos seguintes da análise, por questão de economicidade, além do objetivo deste artigo ser mais voltado para o campo da Ciência da Informação, foram suprimidos. Destacamos como a reflexão teórica que fizemos pela $\mathrm{AD}$ nos permitiu depreender a heterogeneidade e a dispersão da produção dos sentidos que constituem as FD. Ao significar, o sujeito se significa e o gesto de interpretação é o que, perceptível, ou não, para o sujeito e seus interlocutores, decide a direção dos sentidos, segundo uma FD. Na associação do acidente da central nuclear de Fukushima, ainda que de forma indelével, com a explosão da bomba de Hiroshima, feita por um dos artigos listados no Quadro I, circulam as FI's desenvolvidas por correntes anti-nucleares, tanto emergentes das décadas de ameaça do holocausto nuclear pela guerra fria, como pelos emblemas pacifistas encabeçados por entidades de representação mundial.

Os textos falam por si próprios e contam suas próprias histórias, as suas verdades, não transparecendo a subjetividade que lhes é inerente. Neles, observa-se uma unidade narrativa em torno da troca de experiências sociais proporcionadas pelo acidente que lhes deu o tema. Analisando os trechos isoladamente, verificamos a narração de fatos distintos que podem ser considerados fatos em si próprios. Quando tomados em conjunto, porém, vemos que há uma integração intencional, porque uma narrativa nunca está isolada e sim, se entrelaça com outras, atravessadas pela memória discursiva, que é constitutiva do imaginário social. Já nos diz Mariani (1998) que toda narrativa é incompleta. É no narrador e no leitor que encontra sua completude, mas ambos estão assujeitados aos processos históricos e ao lugar social que os ultrapassam. 
As reportagens selecionadas para a análise apresentam enunciados que rememoram acontecimentos, afinal são celebrações de fatos marcantes. Eles naturalmente fazem ecoar discursos já ditos, isto é, retomam formulações de um outro lugar, de outra conjuntura histórico-social. Tais ecos vêm carregados de ideologias. Os vinte e cinco anos que separam o acidente de Chernobyl do de Fukushima são aproximados em tempo e geografia pela ressonância de significação interdiscursiva que os atualiza conforme as práticas sociais de suas leituras. A aproximação das catástrofes repete reações que se observaram em uma realidade diferente, tanto quanto é possível mudar em 25 anos. Mas o que parece mais relevante são os pontos em que os dois são similares. Aqui, a ideologia da mobilização pelo fim da energia nuclear ganha força na constatação de que os clamores contra a tecnologia são reforçados pela ocorrência de novo acidente - sim, a ideologia contrária está do lado da razão. As celebrações, em si mesmas, parecem clamar pelo fim da energia nuclear, simbolizada nos próprios acidentes. É um aniversário de um acidente que é comemorado com outro. Como nada foi feito para derrotar a morte coletiva simbolizada na manifestação, a onda antinuclear marca uma força discursiva. É a FD da ideologia predominante.

\section{Considerações finais}

Trabalhamos, neste artigo, informações veiculadas em reportagens sobre acidentes variados e suas retomadas em variados períodos de tempo. Demos ênfase, porém, à análise daqueles que tiveram o seu evento de origem nuclear, por conta do recorte de pesquisa em que ele está baseado, que busca entender a construção simbólica sobre o discurso do medo atômico. Como a produção discursiva acontece numa conjuntura dada e coloca em movimento formulações anteriores já enunciadas, podemos entender como os mesmos enunciados de dor e dano retornam a cada nova retomada do acontecimento, por si, já de extrema negatividade.

A memória discursiva, como a desenvolvemos neste trabalho, é o que surge dentre a leitura do acontecimento, restabelecendo os pré-construídos e os 
discursos transversos a esse acontecimento, frutos de uma rede simbólica que confirma o que deve ser dito. A teia que parece enredar os discursos dos acidentes nucleares sugere remeter-se constantemente à ideia da bomba e da destruição de uma guerra total.

Pela $\mathrm{AD}$ vimos que a ideologia determina a vinculação do sujeito a certas matrizes de sentido, afastando-se de outras. Refletindo sobre os limites do campo da Memória Social, em sua interdisciplinaridade que o aproxima da Ciência da Informação, comprovamos a sua aproximação pela dimensão discursiva, tal como apontam Dodebei e Orrico (2012), no estabelecimento de um universo simbólico constituído por redes de sentidos.

A detonação das bombas, símbolo do nascimento da tecnologia nuclear, é comemorada mundialmente, a cada ano, como aniversário de uma tragédia humana rememorando o que nunca mais deveria se repetir. Da mesma forma, os grandes acidentes como Bhopal, Bufalo Creek, Mariana, ou as estatísticas estarrecedoras da indústria do petróleo, despertam o mesmo sentimento. Porém, a gravidade dos acidentes no campo da mineração e na indústria química, assim como a frequência com que ocorrem, não conta com a mesma distinção que se observa naqueles de origem na energia atômica. Pudemos observar que a abordagem midiática no tratamento das catástrofes de causa nuclear é marcada pela rememoração do aniversário das bombas e a consequente ameaça de destruição por contaminação radioativa. Esta é uma referência informacional a mais de tratamento jornalístico - uma memória discursiva presente ocasionalmente nos ciclos de rememorações dos acidentes nucleares, algo a mais que os caracterizam como valor de lembrança.

O discurso jornalístico faz a aproximação discursiva das catástrofes por uma repetição de reações que se observaram em realidades diferentes, tanto quanto é possível mudar em 10, 20 ou 30 anos. Mas o que parece mais relevante são os pontos similares entre diferentes acidentes. É que a ideologia da mobilização pelo fim da energia nuclear ganha força pela constatação de que a ocorrência de novos acidentes reforça e justifica esse movimento.

Para encerrar, ressaltamos a não finitude do conflito na $\mathrm{AD}$. Considerando sempre as condições de produção dos discursos, extremamente 
variáveis nos ciclos de tempo em que nos focamos, não existe um espaço completamente estabilizado de conclusões fechadas. Os espaços de tempo cíclico que separam os muitos acidentes nucleares reportados e comemorados pelas reportagens recortadas permitiram constatar a forte dicotomia ressoante de suas leituras. As catástrofes que se observaram em realidades de épocas diferentes, comportando aspectos de origem e causas também diferentes, mostraram em comum a presença do interdiscurso do terror radioativo, o ponto mais forte em que se mostrou similaridade.

$\mathrm{O}$ tema ainda permite maiores argumentações porquanto a $\mathrm{AD}$ não pretende a universalidade e aqui a utilizamos como método complementar aos estudos do campo da informação. Lembrando a relação entre memória e cultura, nos permitimos estabelecer uma ponte entre ações informacionais e práticas discursivas na apreensão das muitas redes de sentido que circulam pelas comunicações dos acidentes de origem tecnológica.

\section{Financiamento}

Conselho Nacional de Desenvolvimento Científico e Tecnológico (PQ2 processo 305755/20153) e Coordenação de Aperfeiçoamento de Pessoal de Nível Superior (código de financiamento 001).

\section{REFERÊNCIAS}

BARBOSA, M. Senhores da memória. Intercom: revista brasileira de ciências da comunicação, São Paulo, v.18, n.2, p. 84-101, jul/dez. 1995.

BARBOSA, V. As cicatrizes nucleares 30 anos após o inferno de Chernobyl. Exame, São Paulo, 16 abr. 2016. Mundo.

BELKIN, N. J.; ROBERTSON, S. E. Information Science and the phenomenon of information. Journal of the American Society for Information Science, Medford, v. 27, n.4, p. 197-204, jul./ago. 1976. CONFERÊNCIA INTERNACIONAL DA COMISSÃO NACIONAL DE ENERGIA NUCLEAR, 1997, Goiânia. Goiania, ten years later. Anais... Viena : IAEA, 1998. 
COURTINE, J. J. Définitions d'orientations théoriques et construction de procédures en analyse du discours. Philosophiques, Québec, v. 9, n. 2, p. 239264, out. 1982.

EM MEIO A NOVA onda anti-nuclear, Ucrânia marca 25 anos de acidente de Chernobyl. BBC NEWS BRASIL, [S.1.], 26 abr. 2011.

ERIKSON, K. A new species of trouble: explorations in disaster, trauma, and community. New York: W. W. Norton \& Company, 1994.

ERLL, A.; NÜNNING, Ansgar. Media and cultural memory. Berlim: Walter de Gruyter, 2008.

FARIAS, F. R.; PINTO, D. S. Memória Social e situação traumática. Morpheus: revista de estudos interdisciplinares em memória social, Rio de Janeiro, v. 9, n. 15, p. 177-202, 2016.

FOLHA DE SÃO PAULO. Com minuto de silêncio, milhares lembram tragédia em Chernobyl. Folha de São Paulo, São Paulo, 26 abr. 2006.

FRANCE PRESSE. Kan defende o abandono da energia nuclear no aniversário de Hiroshima. G1, Rio de Janeiro, 6 ago. 2011. Mundo,

FRANCISCATO, C. E. A temporalidade múltipla no webjornalismo. In: CONGRESSO BRASILEIRO DE CIÊNCIAS DA COMUNICAÇÃO, 32., 2009, Curitiba. Anais eletrônicos... Curitiba: Intercom, 2009.

HALBWACHS, M. A memória coletiva. São Paulo: Vértice, 1990.

INDURSKY, F. Da heterogeneidade do discurso à heterogeneidade do texto e suas implicações no processo da leitura. In: ERNST-PEREIRA, A.; FUNCK, S. B. (Orgs.). A leitura e a escrita como práticas discursivas. Pelotas: Educat, 2001.

KARAZY, Sergei. Vigília lembra 20 anos do desastre de Chernobyl. Reuters, 25 abr. 2006.

MARIANI, B. S. C. Imprensa de 1930 e memória histórica: uma questão para a análise do discurso. 1988. Dissertação (Mestrado em Linguística) -

Universidade Estadual de Campinas, Campinas, 1988.

MARIANI, B. O PCB e a imprensa: os comunistas no imaginário dos jornais (1922-1989). Rio de Janeiro: Editora Revan, 1998.

MARIANI, B. Os primórdios da imprensa no Brasil (ou: de como o discurso jornalístico constrói memória). In: ORLANDI, Eni (Org.). Discurso fundador. Campinas: Pontes, 1993. 
OLICK, J. Reflections on the underdeveloped relations between Journalism and Memory Studies. In: ZELIZER, B.; TENENBOIM-WEINBLATT, K.

Journalism and memory. London: Palgrave Macmillian, 2014. p. 17-31.

ORLANDI, E. P. Análise do discurso: princípios e procedimentos. Campinas: Pontes, 2007.

PÊCHEUX, M. A propósito da análise automática do discurso: atualização e perspectivas. In: GADET, F.; HAK, T. (Org.). Por uma análise automática do discurso. Campinas: Ed. da UNICAMP, 1990.

RICOEUR, P. Tempo e narrativa. Campinas: Papirus, 1994. Tomo I.

ROBINSON, S. 'We were all there:' Remembering America in the anniversary coverage of Hurricane Katrina. Memory Studies, [S. 1.], v. 2, n. 2, p. 235-253, maio 2009.

SILVA JÚNIOR, E. Dez anos de Chernobyl. Folha de São Paulo, São Paulo, 26 set. 1996.

SILVA, H. R. Rememoração: comemoração: as utilizações sociais da memória. Revista Brasileira de História, São Paulo, v. 22, n. 44, 2002.

SILVA, T. C. As Celebrações, a Memória Traumática e os Rituais de Aniversário. Revista UFG, Goiânia, v. 9, n. 1, 2007.

SU, C. One earthquake, two tales: narrative analysis of the tenth anniversary coverage of the 921 Earthquake in Taiwan. Media, Culture \& Society, [S.l.], v. 34, n. 3, p. 280-295, maio 2012.

TARDY, C.; DODEBEI, V. Memória e novos patrimônios. Marseille: Open Edition, 2015.

TURNER, Victor. O processo ritual: estrutura e anti-estrutura. Petrópolis: Vozes, 1982.

VEJA. Chernobyl: pior acidente nuclear da história completa 30 anos. Veja, São Paulo, 26 abr. 2016.

WIZIACK, J. Chernobyl ainda assombra. Isto É, São Paulo, 3 maio 2006. Tecnologia \& Meio ambiente.

\section{Danger in retrospect: how media approaches anniversaries of big accidents caused by technology failures}

Abstract: Although applied to the discourse analysis, this paper discusses the possible connection between the information presented on a media article and its 
repercussion on the social imaginary. By approaching the subjects of information and communication it is possible to think about the impacts on the symbolic cognition of the information social groups. Besides it connects the relation of information and memory. When referring to some of the worst catastrophes in the world, about it considers those which caused more damage to people and environment. Observing journalist discourses used to describe anniversaries of big accidents may be helpful to find out what can be learned on those celebrations promoted by mass media, in order to comprehend their impact on the social imaginary. This paper looks into how the memory of nuclear fear discourse is constructed by considering the accidents anniversaries. It is taken into account the multiple representations for the concept of time in journalism. It is observed that, by celebrating some events, repeating the narration at each time cycle, the media uses it for auto promotion. Time and memory are discursive strategies for journalists, as the several uses of the past bring sense to present events, and so, the value of the news is increased. As an illustration, some magazine articles reporting the nuclear accidents of Chernobyl, in 1986, and Fukushima, in 2011, were collected. The amount of 25 years between them can result in observation and thought about the pre-said and the transverse discourses around them. The whole process is history oriented and demonstrates a dispute on the production of senses.

Keywords: Scientific risk. Discourse. Media. Memory. Celebration.

Recebido: $13 / 11 / 2018$

Aceito: $30 / 05 / 2018$

1 O acidente com o césio-137 ocorreu em Goiânia em de 13 de setembro de 1987, quando uma cápsula com 19 gramas do elemento radioativo foi aberta em um ferro-velho. Quatro pessoas morreram no mês seguinte devido à exposição aguda à radiação. Este é o número oficial de mortes considerado pela Secretaria da Saúde do Estado de Goiás, que tem hoje 943 vítimas cadastradas para receber acompanhamento no Centro de Assistência aos Radioacidentados Leide das Neves Ferreira (fundado no ano seguinte para atender a população afetada).

2 Nos processos discursivos funcionam uma série de formulações imaginárias que designam o lugar que A e B se atribuem cada um a si e ao outro, a imagem que eles fazem do seu próprio lugar e do lugar do outro (PÊCHEUX, 1990). 